\title{
Chemical, morphological and mechanical analysis of sisal fiber-reinforced recycled high-density polyethylene composites
}

\author{
S. L. Fávaro ${ }^{1}$, T. A. Ganzerli 1 , A. G. V. de Carvalho Neto ${ }^{1}$, O. R. R. F. da Silva ${ }^{2}$, E. Radovanovic ${ }^{*}$ \\ 1Universidade Estadual de Maringá, Departamento de Química, Grupo de Materiais Poliméricos e Compósitos, \\ Av. Colombo 5790, 87020-900, Maringá, Paraná, Brazil \\ 2Embrapa Algodão, Rua Osvaldo Cruz, 1143, 58107-720, Campina Grande, Paraíba, Brazil
}

Received 12 January 2010; accepted in revised form 16 March 2010

\begin{abstract}
Natural fibers are widely used as plastic composite material reinforcements. In this work, composites of postconsumer high-density polyethylene (HDPE) reinforced with sisal fibers were prepared. PE and sisal fibers were chemically modified to improve their compatibilities, try to increase the hydrophobic character of the sisal fiber and hydrophilic character HDPE. Sisal was mercerized with a $\mathrm{NaOH}$ solution and acetylated and the PE was oxidized with $\mathrm{KMnO}_{4} \mathrm{Solu}_{-}$ tion. The chemically modified fibers were characterized by Fourier Transformed Infrared Spectroscopy (FTIR) and ${ }^{13} \mathrm{C}$ Nuclear Magnetic Resonance Spectroscopy ( ${ }^{13} \mathrm{C}$ NMR). The composites were prepared by extrusion of modified and unmodified materials containing either 5 or $10 \mathrm{wt} \%$ fibers. The morphology of the obtained materials was evaluated by SEM. The fiber chemical modification improves it adhesion with matrix, but not benefit were obtained with HDPE oxidation. Flexural and impact tests demonstrated that the composites prepared with modified sisal fibers and unmodified PE present improved mechanical performance compared to pure PE.
\end{abstract}

Keywords: polymer composites, recycling, surface treatments, sisal fibers, recycled polyethylene

\section{Introduction}

The increasing use of polymeric materials can be observed in our daily life, in uncounted consumer goods around us. However, the production and use of plastics has a range of environmental impacts. Plastics production requires significant quantities of resources, primarily fossil fuels, both as a raw material and to deliver energy for the manufacturing process. The disposal of plastics products also contributes significantly to their environmental impact. Because most plastics are non-degradable, they take a long time to break down, possibly up to hundreds of years. With more and more plastics products, particularly plastics packaging, being disposed of soon after their purchase, the landfill space required by plastics waste is a growing concern. Thereby, the interest on recycled materials developed from post-consumer polymers has gained an increasing attention. The largest fraction of polymers wastes consist of polyolefins, such as polyethylene (PE) and polypropylene (PP) [1], therefore recycling is an alternative destination for these materials. However, to obtain products from recycled material may be necessary specific properties that are not present in original plastic [2]. The environment friendly alternative way to the modification of some properties of polymers is the utilization of natural fibers forming composite materials, and this area presented a crescent development in the last 20 years [3]. The natural fibers, besides pre-

*Corresponding author, e-mail: eradovanovic@uem.br (C) BME-PT 
senting many advantages in relation to synthetic fibers (low cost, renewability, biodegradability, abundance), could also present better mechanical performance from its composites than the ones obtained with synthetic fibers, for instance, the glass fibers [3-5]. Thus, natural fibers, such as fibers of wood, jute, kenaf, hemp, sisal, pineapple, rice husk, etc, have successfully been applied to improve mechanical properties of plastic composites [6-12].

Among natural fibers, sisal is one of the most used in the world, and Brazil is one of the biggest producers. The exceptional mechanical characteristics of sisal are already making its application in automotive industry and civil construction possible $[13,14]$.

However, like any other hydrophilic lignocellulosic fiber used as reinforcement of hydrophobic plastic in composites, the relatively poor compatibility between them is the barrier to obtain good results. Then, coupling agents are generally used to modify the fiber-matrix interface and thereby enhance the fiber-matrix adhesion $[3,15]$.

In this article, mechanical and morphological properties of composites, prepared from a post-consumer high density polyethylene (PE) as matrix and sisal fibers as reinforcement phase were studied.

\section{Experimental section}

\subsection{Composite preparation}

\subsubsection{Recycled polyethylene surface modification}

The recycled high-density polyethylene was obtained from Plaspet Polymer Recycling Industry - Maringá - PR - Brazil. The polymer was previously hand-separated from other polymers, washed with water, and cut in $\sim 1.5 \mathrm{~mm}$ diameter pellets on site. Before surface modification in laboratory, the polyethylene pellets were washed again and dried at $60^{\circ} \mathrm{C}$ for $8 \mathrm{~h}$. Surface modification conditions were previously determined [16]: the pellets were immersed in a $\mathrm{KMnO}_{4}$, (Nuclear, Brazil), $0.25 \mathrm{~mol} \cdot \mathrm{l}^{-1}$, and solution in $\mathrm{HCl}$ (Nuclear, Brazil), $0.50 \mathrm{~mol} \cdot \mathrm{l}^{-1}$ acidic medium at $25^{\circ} \mathrm{C}$ for $8 \mathrm{~h}$. Hence, the oxidized polyethylene will be labeled PEox and the untreated polymer, PE.

\subsubsection{Sisal fibers surface modification}

The sisal fiber, namely Agave Sisalana variety coming from state of Bahia - Brazil, was kindly supplied by Embrapa Algodão. Sisal was cut between 0.5 and $1.0 \mathrm{~cm}$ of length. Previously to the composite preparation, the sisal was washed with distilled water at $80^{\circ} \mathrm{C}$ for $1 \mathrm{~h}$ and dried in oven at $100^{\circ} \mathrm{C}$ for $5 \mathrm{~h}$. Sisal mercerization was conducted by keeping it in $10 \mathrm{wt} \% \mathrm{NaOH}$ solution at room temperature for $3 \mathrm{~h}$. After mercerization, the sisal was rinsed with water to remove the soda excess until $\mathrm{pH} \sim 7$ was reached and dried in oven at $100^{\circ} \mathrm{C}$ for $3 \mathrm{~h}$. After this, the sisal was acetylated as follows: the fibers were immersed in pure acetic acid at room temperature for $1 \mathrm{~h}$, then removed and immersed in acetic anhydride acidified with $0.1 \mathrm{wt} \%$ sulfuric acid for $5 \mathrm{~min}$ at room temperature. Finally, the samples were rinsed with water until $\mathrm{pH} \sim 7.0$ was reached and dried at $100^{\circ} \mathrm{C}$ for $5 \mathrm{~h}$. The acetylated sisal fibers were labeled Sac, the mercerized ones were labeled Sm, and the unmodified fibers were labeled S.

\subsubsection{Extrusion}

The sisal fibers (modified and unmodified) were incorporated into PE (and PEox) at 5 and $10 \mathrm{wt} \%$. The components were mixed in a lab-made monoscrew extruder with a $25 / 700 \mathrm{~mm}$ (diameter/length) screw $L / D=28$. The cylinder temperature profile was adjusted to 110,155 and $185^{\circ} \mathrm{C}$ for the three heating zones with an average rotation of $40 \mathrm{rpm}$ for all formulations. After extruding, the material was water-cooled down to room temperature.

\subsubsection{Injection moulding}

The mechanical test specimens were obtained by injection moulding in a Pavan Zanet $100 \mathrm{t}$ injection machine with a $42 \mathrm{~mm}$ diameter screw at $180^{\circ} \mathrm{C}$ and injection pressure of 35 bar. The composites prepared were labeled using the representation as in the example: PEox/Sac10, where PEox represents the oxidized polyethylene matrix with $10 \mathrm{wt} \%$ of acetylated sisal fibers as reinforcement. 


\subsection{Characterization techniques}

\subsubsection{Water contact angle}

The water contact angle in the sessile drop method was measured with contact angle meter Cam Micro, Tantec, USA. Each contact angle value was taken as an average value of five different measurements in different parts of two samples fabricated under the same experimental conditions.

\subsubsection{Infrared spectroscopy (FTIR-HATR)}

IR spectra of the polymer and sisal fibers were recorded in a FTIR- Pike Miracle ATR, Digilab Scimitar Series using Horizontal Attenuated Totally Reflectance Fourier Transformed Infrared spectroscopy technique, FTIR-HATR, using a FTIRBOMEM-100 Spectrometer, Canada. The FTIRHATR technique works by passing a radiation beam through a crystal made of a high-refractive index infrared-transmitting material, which is then totally internally reflected at the surface. The sample is brought in contact with the totally reflecting surface of the ATR crystal; the evanescent wave is attenuated in regions of the infrared spectrum where the sample absorbs energy. Each spectrum represents 128 co-added scans rationed against a reference spectrum obtained by recording 128 coadded scans of an empty HATR cell.

\subsection{3. ${ }^{13} \mathrm{C}$ Magic Angle Spinning Nuclear Magnetic Resonance Spectroscopy (13C MAS NMR)}

${ }^{13} \mathrm{C}$ MAS NMR spectra of sisal were recorded in a Varian Mercury Plus BB $300 \mathrm{MHz}$ spectrometer, USA, operating at $75.34 \mathrm{MHz}$ for ${ }^{13} \mathrm{C}$ with contact time of $1 \mathrm{~ms}$ and recycle time of $20 \mathrm{~s}$, and 128 scans for the signal accumulation.

\subsubsection{Scanning electron microscopy (SEM)}

The sisal fibers and the composites were observed using a Shimadzu SS 550 Superscan scanning electron microscope, Japan. The samples were gold coated by sputtering technique and observed under different magnifications. Composite fracture surface analyses were performed after immersing the materials in liquid nitrogen for $10 \mathrm{~min}$.

\subsubsection{Tensile testing}

The composite tensile strength and modulus assays were performed according to the ASTM D-638 test method. The samples were submitted to tensile tests in an EMIC DL 2000 machine (Brazil) at a constant cross-speed of $50 \mathrm{~mm} / \mathrm{min}$. Tensile properties were determined for eight samples of each composition.

\subsubsection{Flexural testing}

The composite flexural strength and modulus were determined, in an EMIC DL 2000 machine (Brazil), using the three-point bending test method following the ASTM D-790-00 A test method. A span of $63 \mathrm{~mm}$ was used in a $5 \mathrm{kN}$ load cell. The load was placed midway between the supports. The crosshead speed applied was $20 \mathrm{~mm} / \mathrm{min}$. The flexural properties were determined for eight samples of each composition.

\subsubsection{Izod impact testing}

The notched Izod impact strength tests were conducted according to ASTM D 256-00 A at room temperature in an EMIC-Al testing machine (Brazil) using a 5.4-J hammer. Each value obtained represented the average of five samples.

\section{Results and discussion}

Table 1 shows the chemical compositions of sisal fibers [17]. The length of sisal is between 1.0 and $1.5 \mathrm{~cm}$ and the diameter is about $100-300 \mu \mathrm{m} \mathrm{[18].}$ The fiber is actually a bundle of hollow sub-fibers. The fibrillar-like structures of fibers can be observed in the fracture image SEM (Figure 1A). Over these structures (Figure 1B) was observed the presence of impurities, composed by parenchymatous cells and others constituents of the fiber as lignin, hemicelluloses and waxes. After alkaline treatment of sisal fibers was observed the extraction of these surface constituents [19] (Figure 1C). Therefore, the exposition of hydroxyl groups

Table 1. The chemical compositions of sisal fibers

\begin{tabular}{|c|c|c|c|}
\hline Cellulose & Hemi-celluloses & Lignin & Ash \\
\hline \multicolumn{4}{|c|}{ (\% by weight) } \\
\hline $43-56$ & $21-24$ & $7-9$ & $0.6-1.1$ \\
\hline
\end{tabular}




$$
\text { cellulose- } \mathrm{OH}+\mathrm{NaOH} \rightarrow \text { cellulose- } \mathrm{ONa}+\mathrm{H}_{2} \mathrm{O}+\text { impurites }
$$
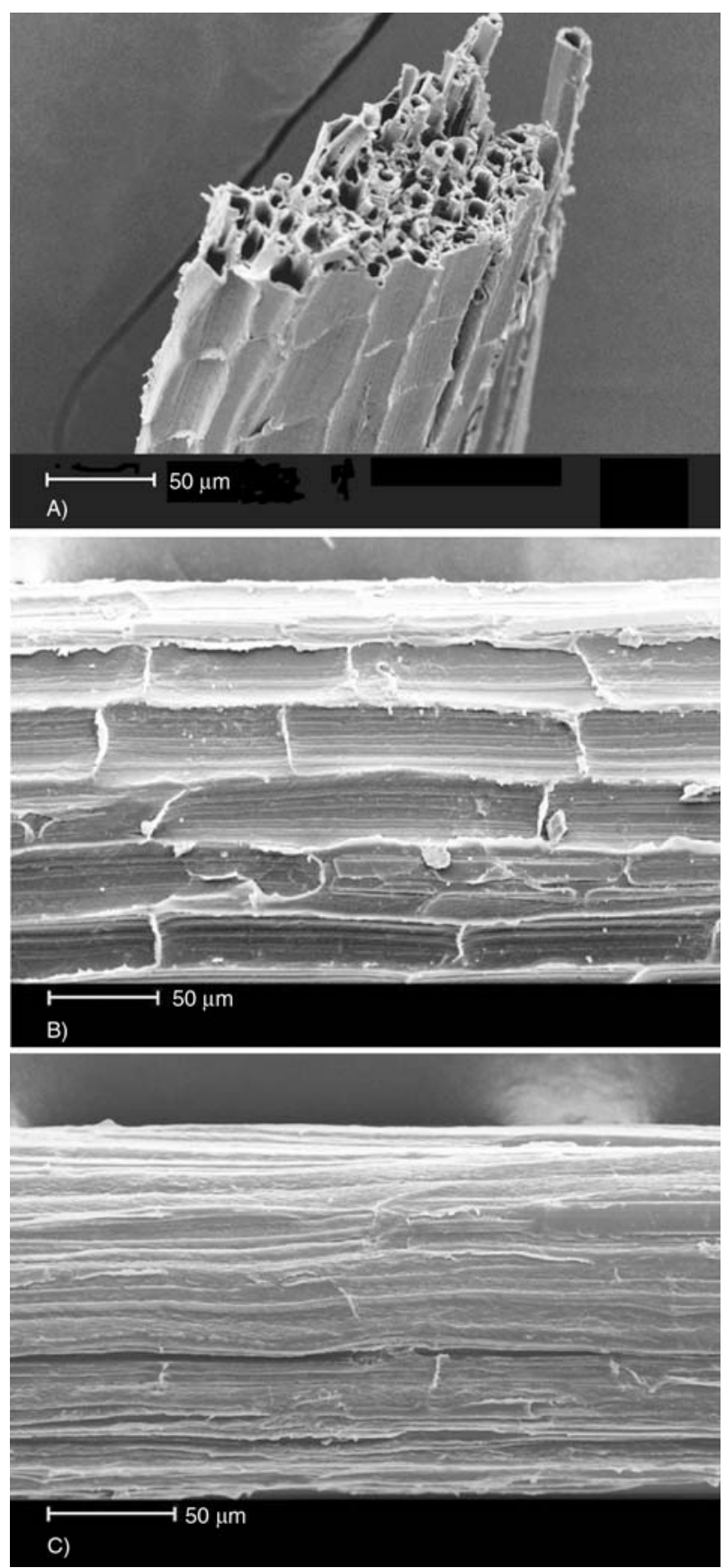

Figure 1. Sisal fiber SEM micrographs: fibrillar structure in fracture image (A), unmodified (B) and mercerized (C) fiber surface images
(Equation (1)) of cellulose microfibers occurred and this treatment should improve the acetylation process of all hydroxyl groups present in the cellulose structure (carbons 2, 3 and 6 in Figure 2) in the acetylating reaction.

The FTIR spectra of S (A), Sm (B), and Sac (C) are shown in Figure 3. Compared with the curve of unmodified sisal, the spectra of mercerized and acetylated cellulose have several differences. After the mercerization process, the bands at 1730 and $1245 \mathrm{~cm}^{-1}$, attributed to the stretching vibrations of $\mathrm{C}=\mathrm{O}$ and $\mathrm{C}-\mathrm{O}$ groups, respectively, disappeared. These kinds of groups are present in lignin and hemicelluloses structures. After acetylating reaction, new acetyl groups were added to cellulose, as indicated in curve $\mathrm{C}$, with the vibrations at $1740 \mathrm{~cm}^{-1}(-\mathrm{C}=\mathrm{O})$ and $1240 \mathrm{~cm}^{-1}(\mathrm{C}-\mathrm{O})$. The spectrum of unmodified cellulose shows an absorption peak at $1375 \mathrm{~cm}^{-1}$ attributed to the $-\mathrm{C}-\mathrm{H}$ bending vibration. After esterification, the added contribution of the acetyl $\left(-\mathrm{C}-\mathrm{CH}_{3}\right)$ stretching vibration intensifies this absorption peak [20,21].

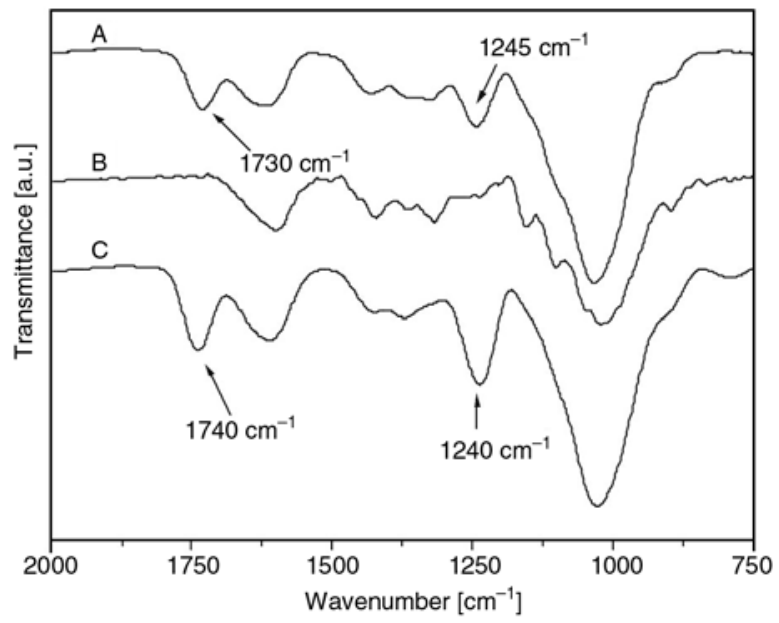

Figure 3. Sisal fibers FTIR-HATR spectra: unmodified (A), mercerized (B), and acetylated (C)

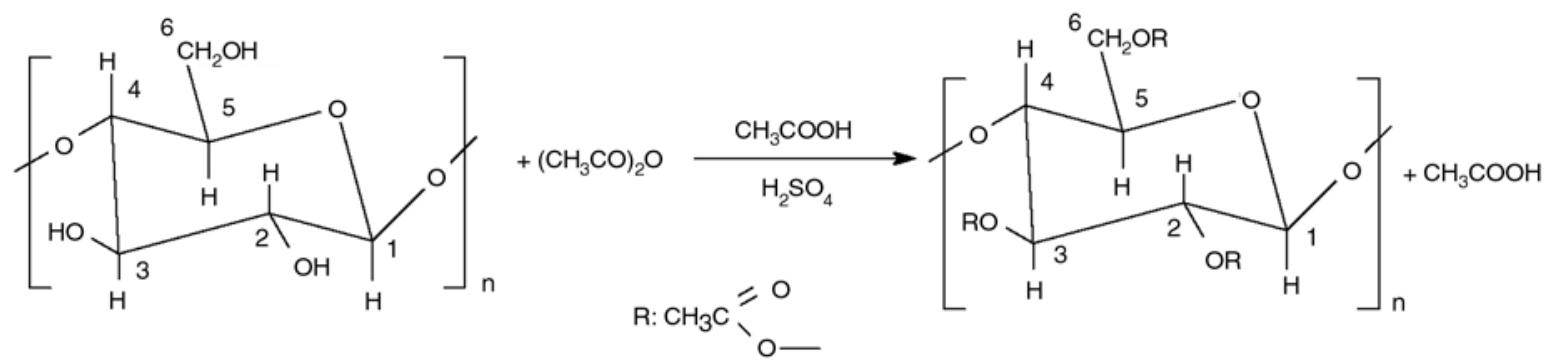

Figure 2. Hydroxyl groups in the cellulose structure 


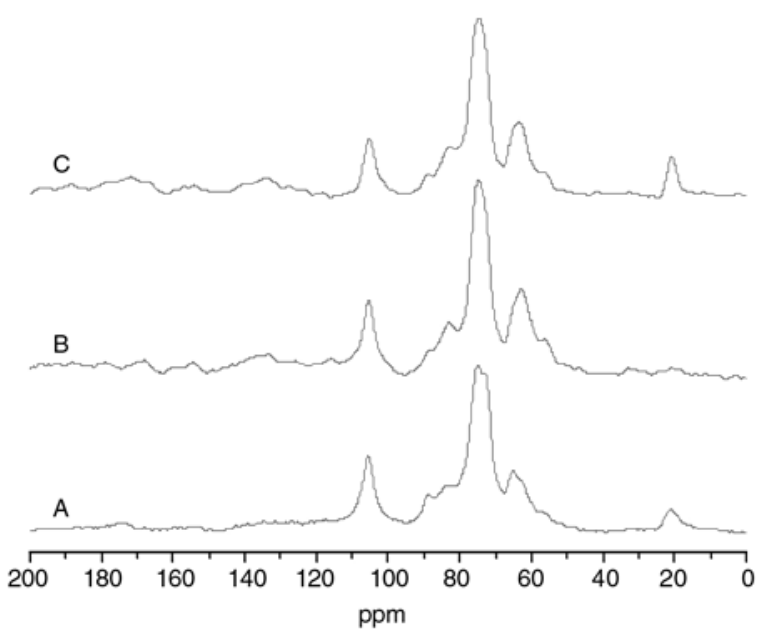

Figure 4. Sisal fibers ${ }^{13} \mathrm{C}$ MAS solid-state NMR spectra: unmodified (A), mercerized (B), and acetylated $(\mathrm{C})$

The mercerization and acetylation reactions of sisal cellulose were also studied by solid-state ${ }^{13} \mathrm{C}$ MAS NMR spectroscopy. The NMR spectra of S (A), Sm (B), and Sac (C) samples are shown in Figure 4. In spectrum A, all noticeable signals of the carbohydrate moiety carbon atoms occur between 50 and $110 \mathrm{ppm}$. The signal at $21 \mathrm{ppm}$ is assigned to the $\mathrm{CH}_{3}$ carbon of the hemicellulose acetyl groups. The signals at 105 ppm (C-1), 89 ppm (C-4 of crystalline cellulose), 84 ppm (C-4 of amorphous cellulose), 75 ppm (C-5), 73 ppm (C-2 and C-3), and $64 \mathrm{ppm}(\mathrm{C}-6)$ have all been reported before [22]. The intensity of C-4 signal at 89 ppm of crystalline cellulose decreased comparatively to the signal at $84 \mathrm{ppm}$, as shown by the comparison of spectrum A to spectra B and C. The C-6 signal in A shifted from 64 to $62 \mathrm{ppm}$ in $\mathrm{B}$ and $\mathrm{C}$. These changes may indicate that the crystalline structure of cellulose was partially disrupted by the break of $\alpha$-cellulose hydrogen bonds by the mercerization and acetylation reactions [23]. The degree of substitution (DS) obtained by acetylation in Sac was 0.90 (substitution of $30 \%$ in the $3 \mathrm{OH}$ groups of each cellulose monomer). This value was obtained by area deconvolution of the peak at $21 \mathrm{ppm}$ in spectrum $\mathrm{C}$ attributed to the $-\mathrm{CH}_{3}$ of the acetyl group generated by the acetylation reaction and related to the deconvoluted area of the peak at 105 ppm (C-1).

Figure 5 shows the FTIR HATR spectra of PE and polyethylene samples oxidized with $\mathrm{KMnO}_{4} / \mathrm{HCl}$ (PEox). The absorption peaks at 2916, 2848, 1463, and $719 \mathrm{~cm}^{-1}$ in A are attributed to methylene nonsymmetric stretching vibration, methylene sym-

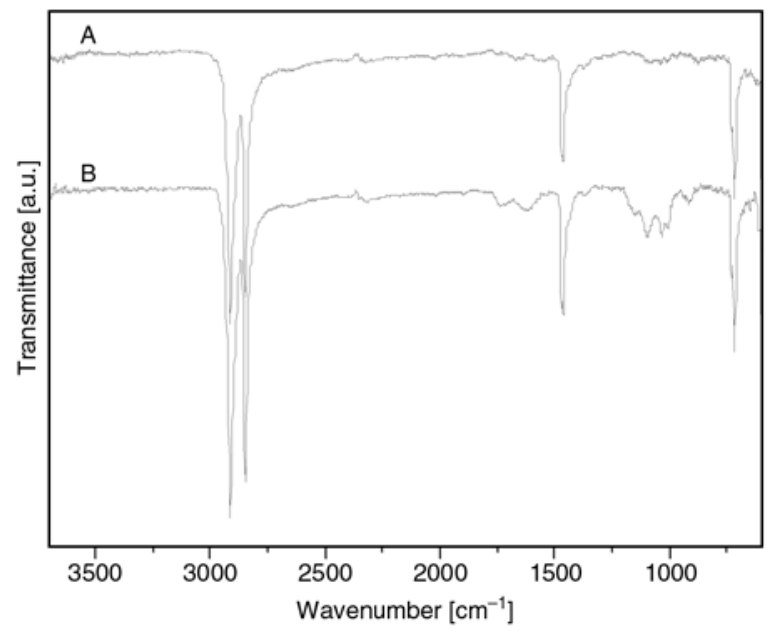

Figure 5. FTIR-HATR spectra of PE (A) and PEox (B)

metric stretching vibration, methylene nonsymmetric changing angle vibration, and methylene swing in plane vibration, respectively. The main changes involving oxidized (spectrum B) and untreated polymers, occurred between 1730 and $1650 \mathrm{~cm}^{-1}$ and between 1100 and $1000 \mathrm{~cm}^{-1}$, are attributed to different $\mathrm{C}=\mathrm{O}$ and $\mathrm{C}-\mathrm{O}$ groups, respectively, created on the polyethylene surface by the $\mathrm{KMnO}_{4} /$ $\mathrm{HCl}$ solution treatment. The increase in the absorption peak intensities at 1645 and $909 \mathrm{~cm}^{-1}$ in the FTIR spectrum may indicates the formation of unsaturated vinyl groups, as already described by other authors $[24,25]$. The oxidation process decreased the polyethylene surface water contact angle in the sessile drop measurements, varying from $92.4^{\circ}$ in PE to $60.0^{\circ}$ in PEox, which decreased the polymer surface hydrophobicity, but did not changed the bulk characteristics [16].

The tensile properties of PE, PEox and composites with 5 and $10 \mathrm{wt} \%$ of either S or Sac are depicted in Figure 6. A gradual decrease in the tensile strength was observed to PE/sisal composites comparatively to that of the pure polymer matrix. The composites with modified PEox and S or Sac presented the lowest tensile strength values. PE/S10 presented values near to the tensile strength value of pure PE. The decrease in the composite tensile strength values may be explained by dewetting effect. The fiber/matrix boundary region stress concentrates around the reinforcement particle. Consequently, the fiber-matrix interaction weakens up, thus, probably leading to debonding at the boundary region. Moreover, the addition of sisal to the polymer matrix increases the tensile modulus significantly 


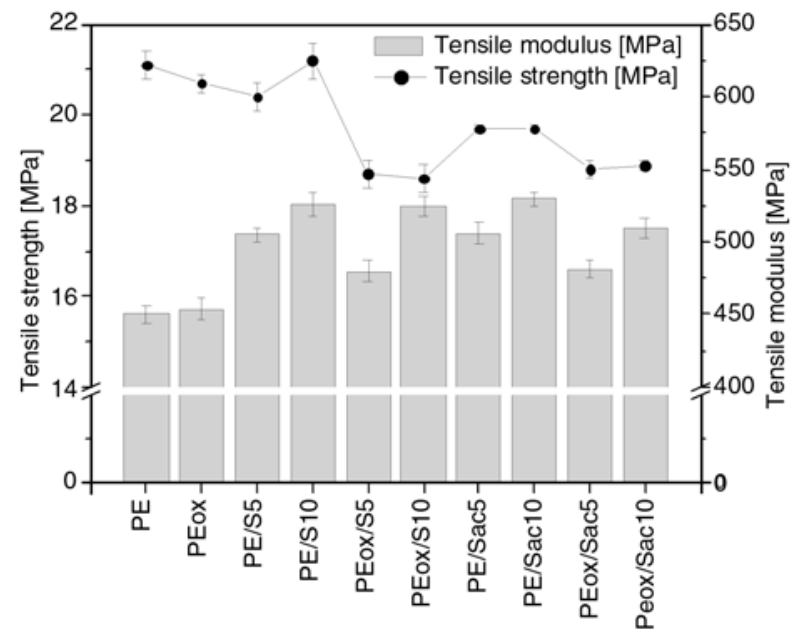

Figure 6. Tensile properties of PE, PEox, PE/sisal and PEox/sisal composites

from almost $450 \mathrm{GPa}$ for $\mathrm{PE}$ to approximately $520 \mathrm{GPa}$ for PE/S10, PE/Sac10, PEox/S and PEox/ $\mathrm{S} 10$, an increase of $16 \%$. Among composites, those with $5 \%$ of reinforcement presented the lowest tensile modulus values.

The flexural properties of PE and four different composites reinforced with either 5 or $10 \mathrm{wt} \%$ sisal fibers are shown in Figure 7. The flexural strength of PE/S5 and PE/S10 was improved by approximately 10 and $15 \%$, respectively. As already observed in the tensile measurements, the flexural strength values of composites containing PEox decreased when compared with those of composites with the same quantity of reinforcement, for instance, the composite $\mathrm{PE} / \mathrm{S} 10$ presented values near to $25 \mathrm{MPa}$, but the composite with the same quantity of fibers and matrix oxidized (PEox/S10) presents values around $22 \mathrm{MPa}$. This result could

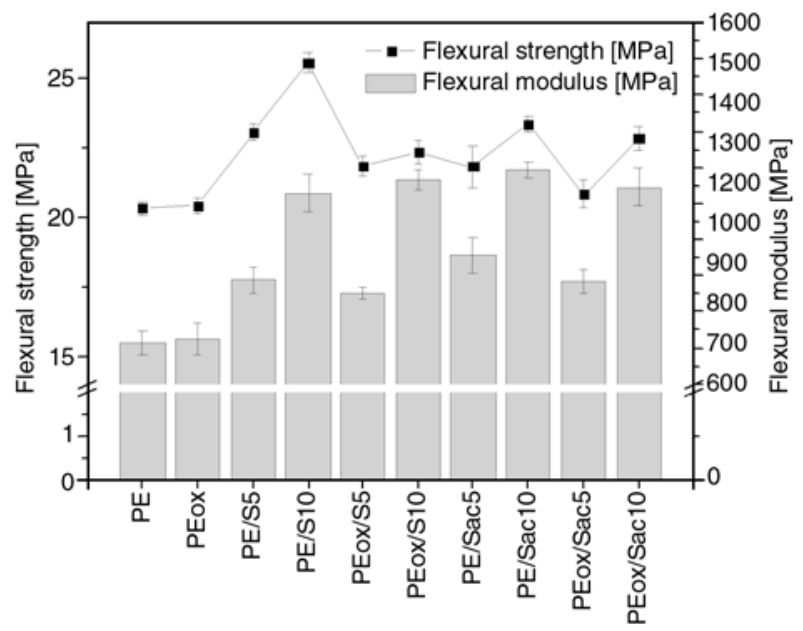

Figure 7. Flexural properties of PE, PEox, PE/sisal and PEox/sisal composites

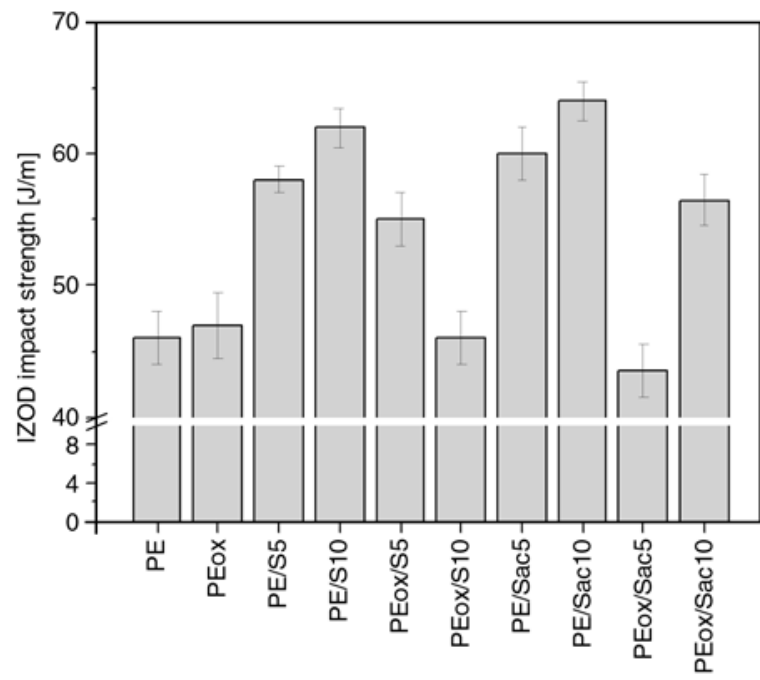

Figure 8. Izod impact properties of of PE, PEox, PE/sisal and PEox/sisal composites

be explained by the absence of phase compatibility between sisal fibers and polymer surface after chemical modification. The flexural modulus increased significantly (c.a. 55\%) in all composites with $10 \%$ of reinforcement.

The Izod impact tests were conducted on notched specimens at room temperature. Figure 8 shows the Izod impact tests of two different compositions of sisal-polyethylene composites. Relative to the pure PE Izod impact strength, the value of acetylated sisal composite (PE/Sac10) is $40 \%$ higher, and the composites with modified matrix (PEox/S and PEox/Sac) presented the lower values.

Figures 9 show the photomicrographs of the polyethylene - sisal composites with $10 \mathrm{wt} \%$ fibers. The samples were fractured in liquid nitrogen prior to observation with scanning electron microscopy (SEM). In the micrographs presented in Figures 9A of composite $\mathrm{PE} / \mathrm{S} 10$ it is possible to observe the nonexistence of phase adherence, which the fiber pullout at the fracture. An increase in adhesion between the phases occurs in the composites prepared with one of the modified materials. For composite $\mathrm{PE} / \mathrm{Sac} 10$, it is possible to observe a high adhesion between the inside of the modified sisal fibers and the unmodified matrix. The modification of polymer also increases the adhesion between the materials (Figure 9C) (absence of pullout), however this behavior is not homogeneous, being that the composites also presents regions of not adherence (Figure 9D). Probably during the composites extrusion process occurred an increase in the mobility of the HDPE chains and the softening of 

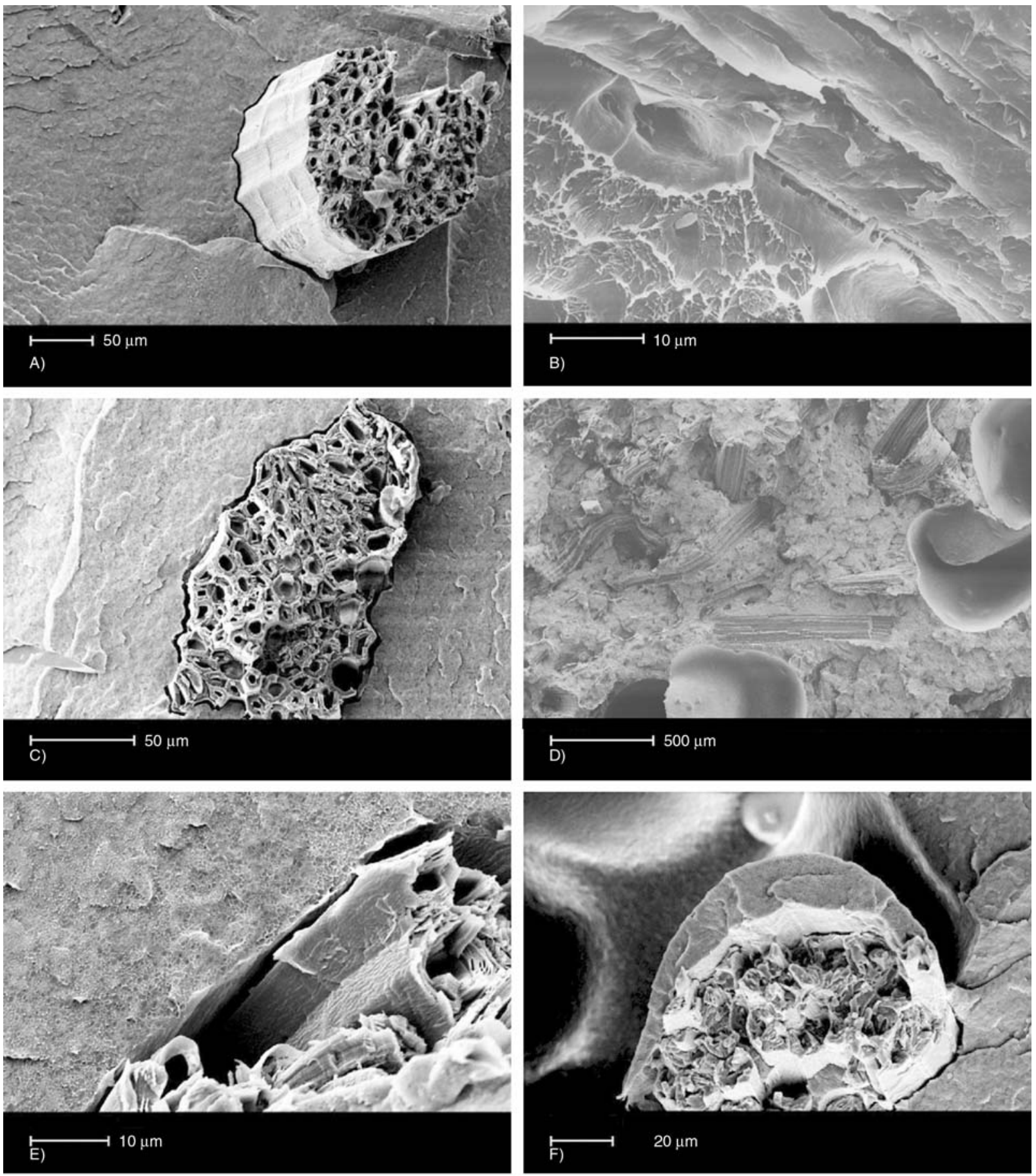

Figure 9. SEM micrographs of composites: PE/S10 (A), PE/Sac10 (B), PEox/S10 (C) and (D), PEox/Sac10 (E) and (F)

polymer, thus, in the end of the extrusion process the fibers could be in contact not only with the oxidized surface polymer, but also with parts not oxidized (bulk). Consequently, the modification of polyethylene surface did not improve mechanical properties of composites. Figures $9 \mathrm{E}$ and $9 \mathrm{~F}$ display the photomicrographs of composite PEox/ Sac10. They show two opposite situations: a significant interfacial interaction between the fiber inside and the matrix, which prevents the fiber pullout at the fracture (Figure 9F), and fiber pullout between nonadhered phases (Figure 9E). The interface adhesion allows stress transfer from the matrix to the fiber and accounts for the superior tensile and flexural modulus of the composites. However, other micrographs (not shown here) show that phase nonadherance predominates in PEox/Sac10, which explains its poor mechanical properties. Nonadherance probably predominates due to the increased in the hydrophilic character of the polymer surface, in 
opposition to the increased hydrophobic character of the sisal fiber surface, related to the acetyl groups that were added to cellulose. The high fiber/ polymer adhesion presented in Figure 9E probably occurred in an unmodified polymer region, such as the inner part of the polymer film.

\section{Conclusions}

Unmodified and oxidized recycled HDPE composites reinforced with unmodified and acetylated sisal fiber were fabricated by extrusion and injection molding. The acetylated sisal fibers were characterized by FTIR, solid-state ${ }^{13}$ C MAS NMR and SEM. The latter was changed by acetylation with a degree of substitution (DS) of 0.90 . The mechanical, chemical, and morphological aspects of different composite compositions (polymer/fiber) were studied. The incorporation of sisal fibers into the PE matrix increased appreciably the tensile and flexural modulus of the composite prepared with $10 \mathrm{wt} \%$ of acetylated sisal fiber and unmodified polyethylene matrix. This composite presented an increase of $40 \%$ in impact strength comparatively to values obtained to pure HDPE. SEM photomicrographs demonstrated the interfacial interaction between acetylated sisal fibers and unmodified PE. The modification of PE did not improve its interaction with modified and unmodified fibers, which explains the poor mechanical properties of its composites.

\section{Acknowledgements}

S. L. Fávaro is grateful to CAPES (Brazil) for her master fellowship. The authors wish to thank CNPq and SETI Fundação Araucária for the financial support and to COMCAP/UEM for scanning electron microscopy images.

\section{References}

[1] Cavalieri F., Padella F.: Development of composite materials by mechanochemical treatment of post-consumer plastic waste. Waste Manage, 22, 913-916 (2002).

DOI: $\underline{10.1016 / \mathrm{S} 0956-053 X(02) 00084-3}$

[2] Dullius J., Ruecker C., Oliveira V., Ligabue R., Einloft S.: Chemical recycling of post-consumer PET: Alkyd resins synthesis. Progress in Organic Coatings, 57, 123-127 (2006).

DOI: 10.1016/j.porgcoat.2006.07.004
[3] Panthapulakkal S., Law S., Sain M.: Enhancement of processability of rice husk filled high-density polyethylene composite profiles. Journal of Thermoplastic Composite Materials, 18, 445-458 (2005).

DOI: $10.1177 / 0892705705054398$

[4] García D., López J., Balart R., Ruseckaite R. A., Stefani P. M.: Composites based on sintering rice huskwaste tire rubber mixtures. Materials and Design, 28, 2234-2238 (2007).

DOI: $10.1016 /$ j.matdes.2006.06.001

[5] Kim H-S., Yang H-S., Kim H-J., Park H-J.: Thermogravimetric analysis of rice husk flour filled thermoplastic polymer composites. Journal of Thermal Analysis and Calorimetry, 76, 395-404 (2004). DOI: 10.1023/B:JTAN.0000028020.02657.9b

[6] Sgriccia N., Hawley M. C.: Thermal, morphological, and electrical characterization of microwave processed natural fiber composites. Composites Science and Technology, 67, 1986-1991 (2007). DOI: 10.1016/j.compscitech.2006.07.031

[7] Bullions T. A., Hoffman D., Gillespie R. A., PriceO'Brien J., Loos A. C.: Contributions of feather fibers and various cellulose fibers to the mechanical properties of polypropylene matrix composites. Composites Science and Technology, 66, 102-114 (2006). DOI: 10.1016/j.compscitech.2005.03.017

[8] Wollerdorfer M., Bader H.: Influence of natural fibres on the mechanical properties of biodegradable polymers. Industrial Crops and Products, 8, 105-112 (1998). DOI: $10.1016 / \mathrm{S} 0926-6690(97) 10015-2$

[9] Fávaro S. L., Lopes M. S., de Carvalho Neto A. G. V., Santana R. R., Radovanovic R.: Chemical, morphological, and mechanical analysis of rice husk/postconsumer polyethylene composites. Composites Part A: Applied Science and Manufacturing, 41, 154-160 (2010).

DOI: 10.1016/j.compositesa.2009.09.021

[10] Sreekumar P. A., Thomas S. P., Saiter J. M., Joseph K., Unnikrishnan G., Thomas S.: Effect of fiber surface modification on the mechanical and water absorption characteristics of sisal/polyester composites fabricated by resin transfer molding. Composites Part A: Applied Science and Manufacturing, 40, 1777-1784 (2009).

DOI: 10.1016/j.compositesa.2009.08.013

[11] Angelini L. G., Lazzeri A., Levita G., Fontanelli D., Bozzi C.: Ramie (Boehmeria nivea (L.) Gaud.) and spanish broom (Spartium junceum L.) fibres for composite materials: Agronomical aspects, morphology and mechanical properties. Industrial Crops and Products, 11, 145-161 (2000).

DOI: $\underline{\text { 10.1016/S0926-6690(99)00059-X }}$

[12] Megiatto J. D., Silva C. G., Ramires E., Frollini E.: Thermoset matrix reinforced with sisal fibers: Effect of the cure cycle on the properties of the biobased composite. Polymer Testing, 28, 793-800 (2009). DOI: $\underline{10.1016 / j . p o l y m e r t e s t i n g .2009 .07 .001}$ 
[13] Bourmaud A., Baley C.: Rigidity analysis of polypropylene/vegetal fibre composites after recycling. Polymer Degradation and Stability, 94, 297-305 (2009).

DOI: $\underline{10.1016 / j . p o l y m d e g r a d s t a b .2008 .12 .010}$

[14] Suppakarn N., Jarukumjorn K.: Mechanical properties and flammability of sisal/PP composites: Effect of flame retardant type and content. Composites Part B: Engineering, 40, 613-618 (2009). DOI: 10.1016/j.compositesb.2009.04.005

[15] Dhakal H. N., Zhang Z. Y., Richardson M. O. W.: Effect of water absorption on the mechanical properties of hemp fibre reinforced unsaturated polyester composites. Composites Science and Technology, 67, 1674-1683 (2007).

DOI: 10.1016/j.compscitech.2006.06.019

[16] Fávaro S. L., Rubira A. F., Muniz E. C., Radovanovic E.: Surface modification of HDPE, PP, and PET films with $\mathrm{KMnO}_{4} / \mathrm{HCl}$ solutions. Polymer Degradation and Stability, 92, 1219-1226 (2007).

DOI: $10.1016 /$ j.polymdegradstab.2007.04.005

[17] Li Y., Mai Y-W., Ye L.: Sisal fibre and its composites: A review of recent developments. Composites Science and Technology, 60, 2037-2055 (2000). DOI: $10.1016 / \mathrm{S} 0266-3538(00) 00101-9$

[18] Bisanda E. T. N., Ansell M. P.: The effect of silane treatment on the mechanical and physical properties of sisal-epoxy composites. Composites Science and Technology, 41, 165-178 (1991). DOI: $\underline{10.1016 / 0266-3538(91) 90026-\mathrm{L}}$
[19] Sreekala M. S., Kumaran M. G., Thomas S.: Oil palm fibers: Morphology, chemical composition, surface modification, and mechanical properties. Journal of Applied Polymer Science, 66, 821-835 (1997).

DOI: $10.1002 /($ SICI) 1097-4628(19971031)66:5<821::

$$
\text { AID-APP2>3.0.CO;2-X }
$$

[20] Lu X., Zhang M. Q., Rong M. Z., Shi G., Yang G. C.: Self-reinforced melt processable composites of sisal. Composites Science and Technology, 63, 177-186 (2003).

DOI: $\underline{10.1016 / \mathrm{S} 0266-3538(02) 00204-X}$

[21] Bower D. I., Maddams W. F.: The vibrational spectroscopy of polymers. Cambridge University Press, Cambridge (1989).

[22] Martins M. A., Forato L. A., Mattoso L. H. C., Colnago L. A.: A solid state ${ }^{13} \mathrm{C}$ high resolution NMR study of raw and chemically treated sisal fibers. Carbohydrate Polymer, 64, 127-133 (2006). DOI: 10.1016/j.carbpol.2005.10.034

[23] Maunu S. L.: NMR studies of wood and wood products. Progress in Nuclear Magnetic Resonance Spectroscopy, 40, 151-174 (2002). DOI: $\underline{10.1016 / \mathrm{S} 0079-6565(01) 00041-3}$

[24] Wu Q., Qu B., Xu Y., Wu Q.: Surface photo-oxidation and photostabilization of photocross-linked polyethylene. Polymer Degradation and Stability, 68, 97-102 (2000).

DOI: $10.1016 / \mathrm{S} 0141-3910(99) 00171-8$

[25] Torikai A., Takeuchi A., Nagaya S., Fueki K.: Photodegradation of polyethylene: Effect of cross linking on the oxygenated products and mechanical properties. Polymer Photochemistry, 7, 199-211 (1986). DOI: $\underline{10.1016 / 0144-2880(86) 90027-8}$ 